\title{
COMPUTER-AIDED DESIGN FOR ANALOG WIRELESS FRONTHAUL OF B5G CELLULAR COMMUNICATION SYSTEMS
}

\author{
Mikhail E. Belkin ${ }^{1}$, Vladislav Golovin ${ }^{2}$, Yuriy Tyschuk ${ }^{2}$, and Alexander S. Sigov ${ }^{1}$ \\ ${ }^{1}$ Scientific and Technological Center "Integrated Microwave Photonics" MIREA - Russian Technological University \\ Moscow, Russian Federation, ${ }^{2}$ Sevastopol State University (SevSU), Sevastopol, Russian Federation
}

NOTE: Corresponding author: Mikhail E. Belkin, belkin@mirea.ru

\begin{abstract}
Specialties of an analog fronthaul based on Radio-over-Fiber architecture and key principles of exploiting microwave photonics technology when designing a millimeter-wave Radio Unit (RU) are reviewed and discussed. To clarify, in this paper we perform a comparative simulation for a specific example of developing an obligatory RU's node as a reference oscillator with an output radio frequency (RF) of more than $100 \mathrm{GHz}$, which is typically implemented by means of a circuit that includes a relatively low-frequency $R F$ oscillator followed by a high-order frequency multiplier. Following the principles and approaches outlined, we propose and describe two alternative schemes for implementing a frequency multiplier from 4.25 to $102 \mathrm{GHz}$ using microwaveelectronics or microwave-photonics approach. Further, using Cadence AWRDE software with an additional introduction of the previously proposed models of optoelectronic devices, their main characteristics are considered. To ensure the practical orientation of the model experiments, the parameters of each of the models used are selected based on the specifications of commercially available discrete components.
\end{abstract}

Keywords - Analog wireless fronthaul, beyond 5G telecommunication system, microwave photonics, modeling, simulation experiment

\section{INTRODUCTION}

As well known, the most striking event for the world of telecommunications in the second decade of the 21st century is the gradual transformation of 5th Generation (5G) cellular networks from a distant perspective into reality, and now the first commercial 5G networks have already been put into operation in a number of industrialized countries [1]. In addition, smartphones and routers with $5 \mathrm{G}$ support have appeared on the market. The main motivation for $5 \mathrm{G}$ onrush is that although mature 4th Generation Long-Term Evolution (4G LTE) networks have provided high rates of data transmission, the exchange of data on the Internet is promptly increasing every year. Here are just a few illustrative examples:

- High Definition (HD) and FullHD videos are replaced by video standards that have many times a higher resolution: 4K UHD and 8K UHD;

- large volumes of personal and corporate data are stored on remote and "cloud" servers and require round-the-clock uninterrupted access;

- technologies of augmented and virtual reality are actively developing, which are planned to be used in the educational process and online games;
- recent advances show that unmanned vehicles that independently choose the route and actively exchange information with each other are no longer fiction, but the near future of mankind.

However, the resources of 4G LTE networks were not designed for the transmission of such huge amounts of information. Despite the use of various complementary technologies such as Multiple Input/Multiple Output (MIMO) and frequency aggregation, Base Stations (BS) in densely populated urban areas are often congested. The result is that newer devices demand faster mobile Internet with lower latency and improved reliability.

When developing 5G NR (New Radio) standards, the exact requirements that new technologies and industries place on mobile communications, were taken into account. Generally, the concept of 5G NR access networks implies three key service scenarios [2-6]:

enhanced Mobile Broadband (eMBB) that supports faster transferring large amounts of user data;

Ultra-Reliable Low Latency Communications (URLLC) that reduces latency, which is critical for the development of unmanned vehicles; 
massive Machine Type Communications (mMTC) that increases connection reliability for different smart devices of the Internet of Things (IoT).

At present, the main interest of a 5G NR network's operators and users is focused on the first point in order to provide super-high-speed transmission of a huge amount of information. Following this need, unlike previous generations of cellular communications, the standard frequency allocation of the $5 \mathrm{G}$ NR wireless fronthaul is divided into two sub-bands: Frequency Range 1 (FR1) in the 1-6 GHz [7] and Frequency Range 2 (FR2) in the 24-71 GHz [8]. The rest of the service scenarios have their own, different from each other, requirements to the accommodating networks, and the Mobile Fronthaul (MFH) and/or Mobile Backhaul (MBH) should be optimized for their implementation [9].

As for a MFH design principle, centralized radio access network (C-RAN) architecture has been already introduced in 4G LTE systems, in which multiple Remote Radio Heads (RRHs) at antenna sites are connected to a single Base Band Unit (BBU) located at a central office so as to enable coordinated control of the multiple RRHs using the Common Public Radio Interface (CPRI) technical standard. However, there is a great issue referred to the link speed for CPRI, which is more than 10 times larger than that of the mobile user data rate mainly due to the quantization process of the radio frequency (RF) signal waveform, especially of millimeter waves (MMW). Since the maximum user data rate in $5 \mathrm{G}$ systems is assumed to be $20 \mathrm{Gbps}$ [10], this interface seems to be unsustainable in 5G NR systems in their current form. To solve this problem, a so-called functional split of the BS configuration was recently standardized into the next generation RAN (NG-RAN) with the introduction of newer functional blocks, such as a Central Unit (CU), a Distributed Unit (DU), and a Radio Unit (RU) instead of a BBU and RRH [1113].

To design optimally NG-RANs using analog Radioover-Fiber (A-RoF) architecture, two options including Radio Frequency-over-Fiber (RFoF) and its derivative Intermediate Frequency-over-Fiber (IFoF) transmission architectures are considered as promising candidates [14]. In addition, the microwave-photonics (MWP) technology [15] is promising for designing the equipment for the RUs of the millimeter and sub-millimeter ranges, in which the updated $5 \mathrm{G}$ and new beyond $5 \mathrm{G}$ (B5G) MFH networks will operate.
Analysis of research articles [12, 13 and the references therein] and Internet communications referred to the latest developments in the field of 5G NR allows us to conclude that for today, world equipment manufacturers have fully mastered the FR1 compatible with 4G LTE and partially the FR2, mainly in its lower sub-band. In its upper part of far beyond $40 \mathrm{GHz}$, the network and user equipment has received the greatest development, providing wireless communications only with fixed network users. The implementation by mobile network users of the all allocated MMW band and prospective operating RFs up to and over $100 \mathrm{GHz}$ using all three of the above service scenarios is considered as the crucial task for wireless fronthaul of 6th generation (6G).

A detailed study of existing approaches to the optimal configurations of B5G networks and our experience in researching the optimal principles for designing analog fronthaul networks with the distribution of RF signals in the MMW band [16-21] suggest that for an NG-RAN, the optimal approach would be to use A-RoF as an architectural concept and MWP as a technological concept for designing an RU containing both optoelectronic and microwave-electronic (MWE) elements. However, the developer of new MWE devices including MWP units is facing a problem of choosing an appropriate computer platform for their modeling and design. In particular, an RU designer is forced to use means of several computer-aided design (CAD) tools because the existing optical and optoelectronic CAD tools (OE-CAD) are not as developed as compared with the CAD tools intended for the modeling of microwaveelectronics devices (ME-CAD) [22]. For example, well-known OE-CAD tool VPI Photonics Design Suite (PDS) allows executing in precision manner the modeling of a fiber-optic link with detailed study of optical units' performances, but RF and especially microwave and millimeter-wave functional units are represented in an idealized manner, without paying attention to the specialties of the microwave band. On the other hand, operating at a symbolic level modern high-power microwave ME-CAD tool Cadence AWRDE simply and with high precision solves this problem but there are completely no models of active optoelectronic components in its library. To fill this gap, we have developed by AWRDE and validated experimentally a number of the models for active and passive MWP elements, such as semiconductor laser, $\mathrm{p}$-i-n photodetector, two types of optical 
modulator, single and multi-core optical fiber, multichannel reflecting Bragg grating, and for some MWP devices using these models. The development results are summarized in [23]. In addition, in order to show the effectiveness and reliability of the proposed approach, a comparative study was carried out using a direct comparison of ME-CAD vs OE-CAD models when simulating both individual optoelectronic elements in a microwave bandwidth and some MWP devices based on them [24]. The result clearly showed that the optimal approach for this purpose was in using established microwave-electronic CAD tool Cadence AWRDE, especially during the modeling of MMW devices, as it is needed for designing analog fronthaul RU of B5G.

Nevertheless, this unit raises the question of choosing the optimal principle for designing its circuitry using an MWE or MWP approach. To clarify this, in this paper we perform a comparative simulation for a specific example of developing such an obligatory RU's node as a reference oscillator with an output frequency of more than $100 \mathrm{GHz}$, which is typically implemented by means of a circuit that includes a relatively low-frequency $\mathrm{RF}$ oscillator followed by a high-order frequency multiplier. Thus, the rest of the paper contains the following. Section 2 addresses the features of configuring an analog fronthaul network using the above two options of RoF architecture. In addition, the key principles of MWP-based hardware design are explained in Section 3. Following the principles and approaches outlined, Section 4 proposes and describes two alternative schemes for implementing a frequency multiplier from 4.25 to $102 \mathrm{GHz}$ using MWE or MWP approach. Further, with the help of AWRDE software with an additional introduction of the previously proposed models of optoelectronic devices, their main characteristics are considered. To ensure the practical orientation of the model experiments, the parameters of each of the models used are selected based on the the specifications of commercially available discrete components. Section 5 concludes the paper.

\section{A-ROF-BASED ARCHITECTURE FOR WIRELESS FRONTHAUL}

In general, a NG-RAN of A-RoF architecture combined with a small-cell scenario is considered as the reliable way for the further development of cellular communication networks beyond 5G. At the same time, due to the relatively small number of user terminals in a picocell, the requirements for cost-efficiency of the RU equipment, in fact, representing the interface between the optical and RF sections of the transmission system come to the forefront. The most obvious solution to this problem is the ultimate simplification of the RU scheme, which is carried out by removing all the processing units (generation, modulation, demodulation, RF frequency conversion, etc.) to the $\mathrm{CU}$ or DU. That is, a package of modulated RF carriers with frequencies corresponding to the operating frequencies of the wireless fronthaul is inputted to the optical transmitters of the DU (downlink) and the RU (uplink). Therefore, the decisive influence on their characteristics effects the scheme of transporting digitally modulated RF signals through a fiber-optic cable between the DU and RU. Fig. 2 illustrates two possible options noted in the Introduction to design NG-RAN wireless fronthaul including RFoF (a), and IFoF (b). The following abbreviations are used in the figure: EA - electronic amplifier; EOM - electro-optic modulator; IFDM - IF demodulator; IFM - IF modulator; IF/RF - frequency up-converter; MIMO - multiple input/multiple output; MMW-RO millimeter-wave reference oscillator; MW-RO microwave reference oscillator; PD photodetector; RF/IF - frequency down-converter; RFDM - RF demodulator; RFM - RF modulator; SLS - semiconductor laser source.

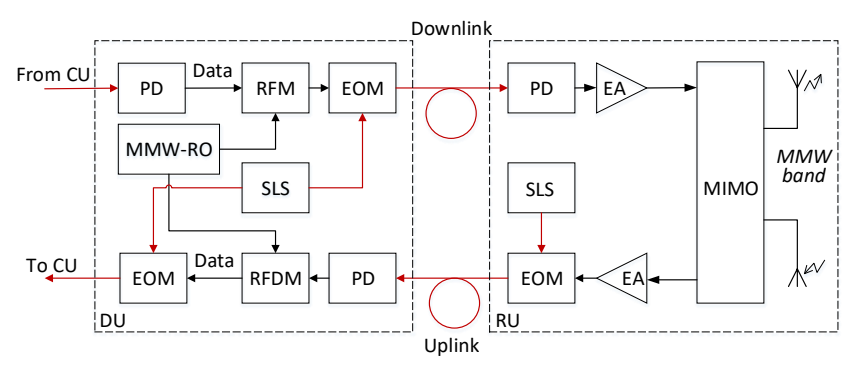

(a) RFoF-based wireless fronthaul

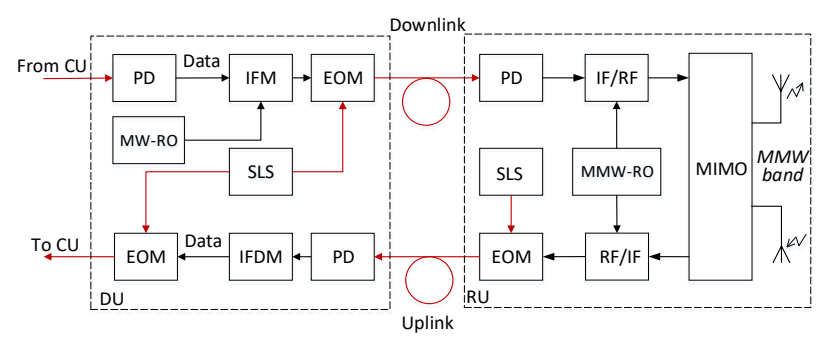

(b) IFoF-based wireless fronthaul

Fig. 1 - Conceptual diagrams of NG-RAN's A-RoF wireless fronthauls (Optical connections are painted in red, electrical connections in black) 
The following conclusions can be drawn from the figure:

- The value of the RF subcarrier in the first option is significantly higher in comparison with the second one, which tightens the requirements for the electronic and optoelectronic components of the DU and RU equipment and, as a result, their cost.

- The option with transmission in the RF band is realized with the least number of transformations on the RU, which minimizes its cost, and, consequently, the cost of the fronthaul network equipment.

However, the fiber-optic transmission of the MMW-band signals has a serious limitation due to the dispersion effect of a standard single-mode optical fiber [15]. Namely, according to the conducted modeling experiments, in which the options for the transmission of optical signals with quadrature amplitude modulation (QAM) at RF of $40 \mathrm{GHz}$ and IF of $15 \mathrm{GHz}$ are compared [16, 21, 25] the maximum permissible distance between the DU and RU, even at such a relatively low MMW frequency, decreases by more than 4 times compared to transmission at the IF, reaching units of $\mathrm{km}$, which is not always provided in real C-RAN fronthauls. It is understood that the situation will become much more critical for B5G NG-RANs using RF subcarriers above $100 \mathrm{GHz}$.

That's why we believe that the optimal approach would be IF-over-Fiber transmission in spite of this option requires an interface at the RU that has to perform RF conversion. Nevertheless, transmission in the IF-band provides flexibility, as there is a simple possibility of RF conversion at a $\mathrm{RU}$, both in the FR1 and in the FR2 (see Introduction).

To effectively implement it in the downlink of Fig. 1 (b), a MMW frequency up-converter is used in the RU scheme, an important element of which is a reference oscillator (RO), the optimal design principle of which will be investigated in Section 4 .

\section{MICROWAVE PHOTONICS APPROACH TO DESIGN ELECTRONICS APPARATUSES}

Microwave photonics is a multidisciplinary scientific branch combining optical, RF, microwave, MMW, and terahertz fields $[15,26,27$ and refs. cited therein]. This field in the last 30 years has attracted immense interest and generated many new R\&Ds from both the scientific community and the commercial sector. Emerging applications for a mobile communication network of RoF architecture, sub-terahertz wireless systems, radar, and electronic warfare systems indicate that MWP is a subject of importance. By common opinion, MWP opens the way to superwide bandwidth characteristics at lower size, weight, and power as compared with traditional means. Fig. 2 depicts typical arrangements of MWP subassembly. As it follows, a photonic processing unit (PPU) is inserted between two optoelectronics modules that are electrical-to-optical (E/O) and optical-to-electrical $(\mathrm{O} / \mathrm{E})$ converters. The first one usually includes a semiconductor laser source (SLS) and electro-optic modulator (EOM) as E/O converter. The second one typically contains a pinphotodetector (PD) followed by a low-noise electronic amplifier (EA). Typical functions of the PPU are transmission, switching, distribution, filtration, time-delaying, and up/down frequency conversion of RF signals in an optical domain. An example of the last operation in relation to the $\mathrm{RF}$ multiplier circuit including in the reference oscillator of $102 \mathrm{GHz}$ for the NG-RAN RU (see Fig. 1 (b)) will be discussed in Section 4.

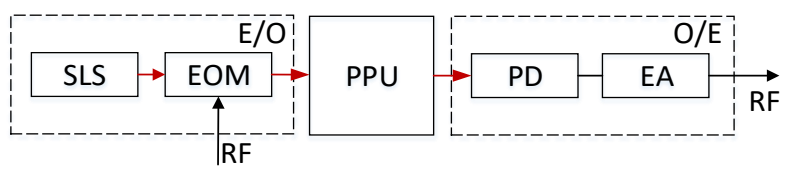

Fig. 2 - Conceptual diagram of MWP subassembly (Optical connections are painted in red, electrical connections in black)

\section{COMPARATIVE COMPUTER-AIDED DESIGN OF MMW FREQUENCY MULTIPLIER}

In the section, we propose and describe two alternative schemes for implementing a frequency multiplier from 4.25 to $102 \mathrm{GHz}$ using an MWE or MWP approach. The goal of the simulation is to select an optimal design concept for developing a high-order RF multiplier of NG-RAN's reference oscillator using the same input and output powers and frequencies. For both cases, Cadence AWRDE software with an additional introduction of the previously proposed models of optoelectronic devices is implemented. To ensure the practical orientation of the simulation experiments, the parameters of the active and passive schematic elements are selected based on the data sheets of the specific manufactured devices. Table 1 lists the common reference data for the simulation. 
4.1 The block diagrams and reference data for simulation

The block diagram of the MWE-assisted RF multiplier under study based on a typical approach to designing high-order MMW multipliers [28] is shown in Fig. 3.

Table 1 - Common reference data

\begin{tabular}{|c|c|}
\hline Parameter & Value \\
\hline \hline Input frequency & $4.25 \mathrm{GHz}$ \\
\hline Output frequency & $102 \mathrm{GHz}$ \\
\hline Multiplication factor & 24 \\
\hline Input power & $\geq 5 \mathrm{dBm}$ \\
\hline Transmission gain & $\geq-5 \mathrm{~dB}$ \\
\hline
\end{tabular}

As it follows from the figure, due to the fact that a high-order coaxial frequency multiplier is practically impossible to implement in the microwave range [28], the circuit is divided into 3 stages of active multipliers by 2 (MP2-1, MP2-2, and MP2-3), followed by a multiplier by 3 (MP3) in a coaxial-waveguide design. To eliminate the higher harmonics arising in the process of this nonlinear operation, after each multiplication stage the corresponding bandpass filters (BPF1, BPF2, BPF3 and BPF4) are introduced. Reference data for simulating this RF multiplier are given in Table. 2. The parameters of all devices are taken from the websites of the respective manufacturers.

The block diagram of the MWP-assisted RF multiplier under study based on a known MWP approach to designing high-order MMW multiplier [29] is shown in Fig. 4. As it follows from the figure, the circuit is divided into 2 stages based on optical Mach-Zehnder modulators (MZM) pumped by the same semiconductor laser source (SLS). The MZM1 of the first one operates in the maximum transmission bias (MATB) mode implementing $4 \mathrm{x}$ multiplication of the input RF signal (4.25 to $17 \mathrm{GHz}$ ). Its output intensity-modulated optical spectrum including optical carrier and a set of higher harmonics of the RF subcarrier is converted by a photodetector (PD1) into an RF band, amplified by an electrical amplifier (EA), and the component of $17 \mathrm{GHz}$ is selected using an RF bandpass filter (RF BPF). The output signal of the $\mathrm{RF} B P F$ is fed to the input of the second MZM2 that operates in the minimum transmission bias (MITB) mode implementing 6x multiplication (17 to 102 $\mathrm{GHz}$ ). Its output intensity-modulated optical spectrum including a partly suppressed optical carrier and a set of higher harmonics of the RF subcarrier is filtered by an optical Bragg grating notch filter (OBGF) suppressing an optical carrier and the two nearest harmonics of the RF signal. The remainder is gained by an optical amplifier (OA), converted by a photodetector (PD2) into an RF band, amplified by EA3, and filtered by a waveguide bandpass filter (WG-BPF). Reference data for simulating this RF multiplier is given in Table. 3. The parameters of all devices are taken from the websites of the respective manufacturers.

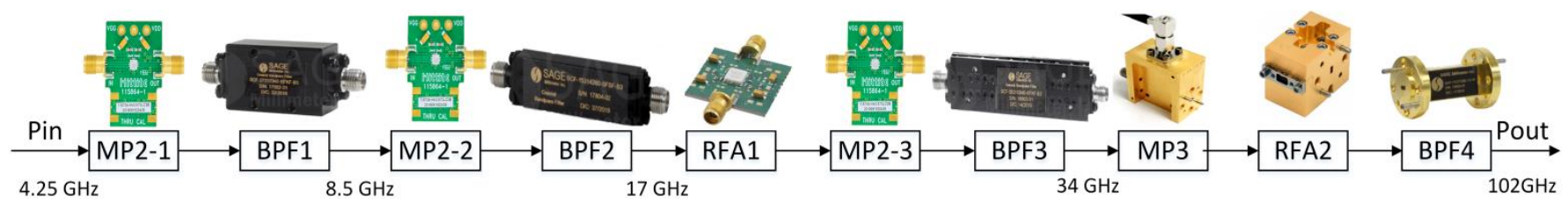

Fig. 3 - Block diagram of the MWE-based frequency multiplier under study

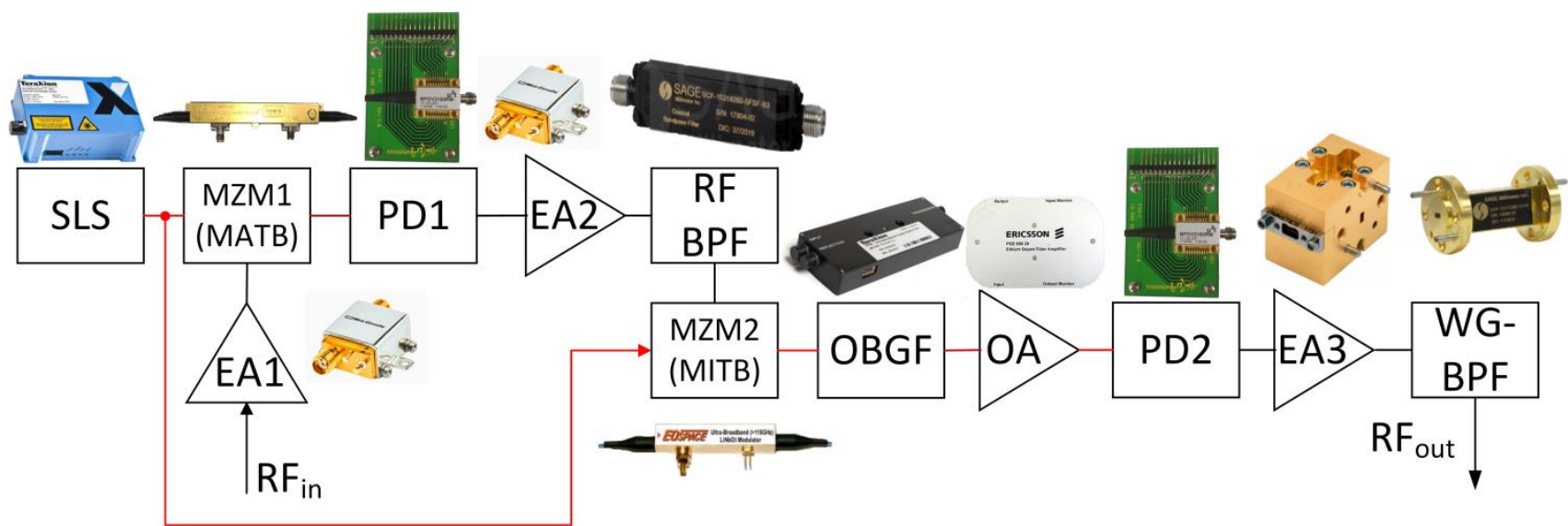

Fig. 4 - Block diagram of the MWP-based frequency multiplier under study (Optical connections are painted in red, electrical connections in black) 
Table 2 - Reference data for the simulation experiments referred to MWE approach (Fig. 3)

\begin{tabular}{|c|c|c|c|c|}
\hline \multicolumn{2}{|c|}{ Element Manufacturer } & Model & \multirow{2}{*}{\begin{tabular}{|l|} 
Parameter \\
Input \\
frequency \\
range
\end{tabular}} & \multirow{2}{*}{\begin{tabular}{|c|} 
Value \\
$4-11 \mathrm{GHz}$
\end{tabular}} \\
\hline \multirow{4}{*}{$\begin{array}{l}\text { MP2-1, } \\
\text { MP2-2 }\end{array}$} & \multirow{4}{*}{$\begin{array}{l}\text { Analog } \\
\text { Devices }\end{array}$} & \multirow{4}{*}{ HMC573LC3 } & & \\
\hline & & & \begin{tabular}{|l|} 
Output \\
frequency \\
range
\end{tabular} & $8-22 \mathrm{GHz}$ \\
\hline & & & $\begin{array}{l}\text { Typical } \\
\text { output } \\
\text { power }\end{array}$ & $12 \mathrm{dBm}$ \\
\hline & & & $\begin{array}{l}\text { Typical F0 } \\
\text { isolation }\end{array}$ & $20 \mathrm{dBc}$ \\
\hline \multirow{3}{*}{ BPF1 } & \multirow{3}{*}{$\begin{array}{c}\text { Eravant } \\
\text { (formerly } \\
\text { SAGE } \\
\text { Millimeter) }\end{array}$} & \multirow{3}{*}{$\begin{array}{c}\text { SCF- } \\
96222270\end{array}$} & \begin{tabular}{|l|} 
Bandpass \\
frequencies
\end{tabular} & $\begin{array}{c}8.5- \\
10.7 \mathrm{GHz}\end{array}$ \\
\hline & & & \begin{tabular}{l|} 
Bandpass \\
insertion \\
loss
\end{tabular} & $1 \mathrm{~dB}$ \\
\hline & & & $\begin{array}{l}\text { Low } \\
\text { side/high } \\
\text { side } \\
\text { rejection } \\
\end{array}$ & $70 / 70 \mathrm{~dB}$ \\
\hline \multirow{3}{*}{ BPF2 } & \multirow{3}{*}{$\begin{array}{l}\text { Eravant } \\
\text { (formerly } \\
\text { SAGE } \\
\text { Millimeter) }\end{array}$} & \multirow{3}{*}{$\begin{array}{c}\text { SCF- } \\
17304240\end{array}$} & $\begin{array}{l}\text { Bandpass } \\
\text { frequencies }\end{array}$ & $\begin{array}{c}16.94- \\
17.34 \mathrm{GHz}\end{array}$ \\
\hline & & & $\begin{array}{l}\text { Bandpass } \\
\text { insertion } \\
\text { loss } \\
\end{array}$ & $1.5 \mathrm{~dB}$ \\
\hline & & & $\begin{array}{l}\text { Low } \\
\text { side/high } \\
\text { side } \\
\text { rejection } \\
\end{array}$ & $40 / 40 \mathrm{~dB}$ \\
\hline \multirow{3}{*}{ RFA } & \multirow{3}{*}{$\begin{array}{l}\text { Analog } \\
\text { Devices }\end{array}$} & \multirow{3}{*}{ HMC1082LP4 } & $\begin{array}{l}\text { Frequency } \\
\text { response }\end{array}$ & $\begin{array}{c}5.5- \\
18 \mathrm{GHz}\end{array}$ \\
\hline & & & Gain & $22 \mathrm{~dB}$ \\
\hline & & & OIP3 & $35 \mathrm{dBm}$ \\
\hline \multirow{4}{*}{ MP2-3 } & \multirow{4}{*}{$\begin{array}{l}\text { Analog } \\
\text { Devices }\end{array}$} & \multirow{4}{*}{ HMC598 } & \begin{tabular}{|l} 
Input \\
frequency \\
range \\
\end{tabular} & $11-23 \mathrm{GHz}$ \\
\hline & & & $\begin{array}{l}\text { Output } \\
\text { frequency } \\
\text { range } \\
\end{array}$ & $22-46 \mathrm{GHz}$ \\
\hline & & & $\begin{array}{l}\text { Typical } \\
\text { output } \\
\text { power } \\
\end{array}$ & $15 \mathrm{dBm}$ \\
\hline & & & $\begin{array}{l}\text { Typical } F_{0} \\
\text { isolation }\end{array}$ & $20 \mathrm{dBc}$ \\
\hline \multirow{3}{*}{ BPF3 } & \multirow{3}{*}{$\begin{array}{l}\text { Eravant } \\
\text { (formerly } \\
\text { SAGE } \\
\text { Millimeter) }\end{array}$} & \multirow{3}{*}{$\begin{array}{c}\text { SCF- } \\
35310340\end{array}$} & \begin{tabular}{|l|} 
Bandpass \\
frequencies
\end{tabular} & $30-40 \mathrm{GHz}$ \\
\hline & & & \begin{tabular}{|l|} 
Bandpass \\
insertion \\
loss
\end{tabular} & $1 \mathrm{~dB}$ \\
\hline & & & $\begin{array}{l}\text { Low } \\
\text { side/high } \\
\text { side } \\
\text { rejection }\end{array}$ & $40 / 40 \mathrm{~dB}$ \\
\hline MP3 & $\begin{array}{l}\text { Virginia } \\
\text { Diodes }\end{array}$ & WR8.0x3 & $\begin{array}{l}\text { Input } \\
\text { frequency } \\
\text { range }\end{array}$ & $30-46 \mathrm{GHz}$ \\
\hline
\end{tabular}

\begin{tabular}{|c|c|c|c|c|}
\hline \multicolumn{2}{|c|}{ Element|Manufacturer } & \multirow[t]{4}{*}{ Model } & Parameter & Value \\
\hline & & & $\begin{array}{l}\text { Output } \\
\text { frequency } \\
\text { range }\end{array}$ & $\begin{array}{c}90- \\
140 \mathrm{GHz}\end{array}$ \\
\hline & & & $\begin{array}{l}\text { Input } \\
\text { power }\end{array}$ & $\begin{array}{c}20- \\
240 \mathrm{~mW}\end{array}$ \\
\hline & & & Harmonics & $-20 \mathrm{dBc}$ \\
\hline \multirow{3}{*}{ RFA2 } & \multirow{3}{*}{$\begin{array}{c}\text { Eravant } \\
\text { (formerly } \\
\text { SAGE } \\
\text { Millimeter) }\end{array}$} & \multirow{3}{*}{$\begin{array}{c}\text { SBL- } \\
6531243550\end{array}$} & $\begin{array}{l}\text { Frequency } \\
\text { range }\end{array}$ & $\begin{array}{c}65- \\
120 \mathrm{GHz}\end{array}$ \\
\hline & & & Gain & $35 \mathrm{~dB}$ \\
\hline & & & Noise figure & $5 \mathrm{~dB}$ \\
\hline \multirow{3}{*}{ BPF4 } & \multirow{3}{*}{$\begin{array}{c}\text { Eravant } \\
\text { (formerly } \\
\text { SAGE } \\
\text { Millimeter) }\end{array}$} & \multirow{3}{*}{$\begin{array}{c}\text { SWF- } \\
\text { 10404340- } \\
10-B 1\end{array}$} & $\begin{array}{l}\text { Bandpass } \\
\text { frequencies }\end{array}$ & $\begin{array}{c}98- \\
102 \mathrm{GHz}\end{array}$ \\
\hline & & & $\begin{array}{l}\text { Bandpass } \\
\text { insertion } \\
\text { loss }\end{array}$ & $2 \mathrm{~dB}$ \\
\hline & & & $\begin{array}{l}\text { Low } \\
\text { side/high } \\
\text { side } \\
\text { rejection }\end{array}$ & $40 / 40 \mathrm{~dB}$ \\
\hline
\end{tabular}

Table 3 - Reference data for the simulation experiments referred to MWP approach (Fig. 4)

\begin{tabular}{|c|c|c|c|c|}
\hline Element & Manufacturer & Model & Parameter & Value \\
\hline \multirow{4}{*}{ SLS } & \multirow{4}{*}{ Teraxion } & \multirow{4}{*}{ NLL } & \begin{tabular}{|l|}
$\begin{array}{l}\text { Wavelength } \\
\text { range }\end{array}$ \\
\end{tabular} & \begin{tabular}{|c|}
$1525-$ \\
$1565 \mathrm{~nm}$ \\
\end{tabular} \\
\hline & & & \begin{tabular}{|l|} 
Output \\
power
\end{tabular} & $80 \mathrm{~mW}$ \\
\hline & & & Linewidth & $10 \mathrm{kHz}$ \\
\hline & & & $\begin{array}{l}\text { Frequency } \\
\text { noise }(1- \\
100 \mathrm{kHz})\end{array}$ & $\begin{array}{l}<2 \times 10^{4} \\
\mathrm{~Hz}^{2} / \mathrm{Hz}\end{array}$ \\
\hline \multirow{5}{*}{ MZM1 } & \multirow{5}{*}{ ThorLabs } & \multirow{5}{*}{ LN05S-FG } & $\begin{array}{l}\text { Wavelength } \\
\text { range }\end{array}$ & $\begin{array}{c}1525- \\
1605 \mathrm{~nm}\end{array}$ \\
\hline & & & $\begin{array}{l}\text { Insertion } \\
\text { loss }\end{array}$ & $5 \mathrm{~dB}$ \\
\hline & & & $\begin{array}{l}\text { Optical } \\
\text { extinction } \\
\text { ratio }\end{array}$ & $20 \mathrm{~dB}$ \\
\hline & & & Bandwidth & $35 \mathrm{GHz}$ \\
\hline & & & $\begin{array}{l}\text { Maximum } \\
\text { RF power }\end{array}$ & $24 \mathrm{dBm}$ \\
\hline \multirow{4}{*}{ EA1 } & \multirow{4}{*}{ Analog Devices } & \multirow{4}{*}{ HMC637 } & $\begin{array}{l}\text { Frequency } \\
\text { range }\end{array}$ & $0.1-6 \mathrm{GHz}$ \\
\hline & & & Gain & $13 \mathrm{~dB}$ \\
\hline & & & $\begin{array}{l}\text { P1dB } \\
\text { output } \\
\text { power }\end{array}$ & $29 \mathrm{dBm}$ \\
\hline & & & Noise figure & $5 \mathrm{~dB}$ \\
\hline \multirow{4}{*}{ PD1 } & \multirow{4}{*}{$\begin{array}{l}\text { II-VI (formerly } \\
\text { Finisar) }\end{array}$} & \multirow{4}{*}{ BPDV2150 } & $\begin{array}{l}\text { Wavelength } \\
\text { range }\end{array}$ & \begin{tabular}{|c|}
$1525-$ \\
$1575 \mathrm{~nm}$
\end{tabular} \\
\hline & & & Bandwidth, & $0-43 \mathrm{GHz}$ \\
\hline & & & Responsivity & $0.6 \mathrm{~A} / \mathrm{W}$ \\
\hline & & & $\begin{array}{l}\text { Maximum } \\
\text { Optical } \\
\text { Input } \\
\text { Power }\end{array}$ & $16 \mathrm{dBm}$ \\
\hline \multirow{3}{*}{ EA2 } & \multirow{3}{*}{ Analog Devices } & \multirow{3}{*}{$\begin{array}{c}\text { HMC1082L } \\
\text { P4 }\end{array}$} & $\begin{array}{l}\text { Frequency } \\
\text { response }\end{array}$ & $\begin{array}{c}5.5- \\
18 \mathrm{GHz}\end{array}$ \\
\hline & & & Gain & $22 \mathrm{~dB}$ \\
\hline & & & OIP3 & $35 \mathrm{dBm}$ \\
\hline
\end{tabular}




\begin{tabular}{|c|c|c|c|c|}
\hline Element & Manufacturer & Model & Parameter & Value \\
\hline \multirow{3}{*}{ RF BPF } & \multirow{3}{*}{$\begin{array}{c}\text { Eravant } \\
\text { (formerly SAGE } \\
\text { Millimeter) }\end{array}$} & \multirow{3}{*}{$\begin{array}{c}\text { SCF- } \\
17304240\end{array}$} & $\begin{array}{l}\text { Bandpass } \\
\text { frequencies }\end{array}$ & $\begin{array}{c}16.94- \\
17.34 \mathrm{GHz}\end{array}$ \\
\hline & & & $\begin{array}{l}\text { Bandpass } \\
\text { insertion } \\
\text { loss }\end{array}$ & $1.5 \mathrm{~dB}$ \\
\hline & & & $\begin{array}{l}\text { Low } \\
\text { side/high } \\
\text { side } \\
\text { rejection }\end{array}$ & $40 / 40 \mathrm{~dB}$ \\
\hline \multirow{5}{*}{ MZM2 } & \multirow{5}{*}{ EOspace } & \multirow{5}{*}{ Custom } & $\begin{array}{l}\text { Wavelength } \\
\text { range }\end{array}$ & $\begin{array}{c}1525- \\
1565 \mathrm{~nm}\end{array}$ \\
\hline & & & \begin{tabular}{|l|} 
Insertion \\
loss \\
\end{tabular} & $7 \mathrm{~dB}$ \\
\hline & & & $\begin{array}{l}\text { Optical } \\
\text { extinction } \\
\text { ratio } \\
\end{array}$ & $20 \mathrm{~dB}$ \\
\hline & & & Bandwidth & $110 \mathrm{GHz}$ \\
\hline & & & $\begin{array}{l}\text { Maximum } \\
\text { RF power }\end{array}$ & $18 \mathrm{dBm}$ \\
\hline \multirow{5}{*}{ OBGF } & \multirow{5}{*}{ Teraxion } & \multirow{5}{*}{ TFN } & $\begin{array}{l}\text { Wavelength } \\
\text { range }\end{array}$ & $\begin{array}{c}1525- \\
1565 \mathrm{~nm}\end{array}$ \\
\hline & & & Bandwidth & $2-50 \mathrm{GHz}$ \\
\hline & & & \begin{tabular}{|l|} 
Insertion \\
loss
\end{tabular} & $\leq 3.5 \mathrm{~dB}$ \\
\hline & & & SMSR & $>20 \mathrm{~dB}$ \\
\hline & & & $\begin{array}{l}\begin{array}{l}\text { Maximum } \\
\text { input } \\
\text { power }\end{array} \\
\end{array}$ & $500 \mathrm{~mW}$ \\
\hline \multirow{4}{*}{$\mathrm{OA}$} & \multirow{4}{*}{ Ericsson } & \multirow{4}{*}{ PGE 60830} & $\begin{array}{l}\text { Wavelength } \\
\text { range }\end{array}$ & $\begin{array}{c}1540- \\
1560 \mathrm{~nm}\end{array}$ \\
\hline & & & Gain & $20 \mathrm{~dB}$ \\
\hline & & & $\begin{array}{l}\text { Maximum } \\
\text { output } \\
\text { power }\end{array}$ & $13 \mathrm{dBm}$ \\
\hline & & & Noise ratio & $5 \mathrm{~dB}$ \\
\hline \multirow{4}{*}{ PD2 } & \multirow{4}{*}{$\begin{array}{l}\text { II-VI (formerly } \\
\text { Finisar) }\end{array}$} & \multirow{4}{*}{$\begin{array}{c}\text { XPDV4121 } \\
\mathrm{R}\end{array}$} & $\begin{array}{l}\text { Wavelength } \\
\text { range }\end{array}$ & $\begin{array}{c}1525- \\
1575 \mathrm{~nm}\end{array}$ \\
\hline & & & Bandwidth, & $0-105 \mathrm{GHz}$ \\
\hline & & & \begin{tabular}{|l} 
Responsivity \\
\end{tabular} & $0.6 \mathrm{~A} / \mathrm{W}$ \\
\hline & & & \begin{tabular}{|l} 
Maximum \\
Optical \\
Input \\
Power
\end{tabular} & $10 \mathrm{dBm}$ \\
\hline \multirow{3}{*}{ EA3 } & \multirow{3}{*}{$\begin{array}{c}\text { Eravant } \\
\text { (formerly SAGE } \\
\text { Millimeter) }\end{array}$} & \multirow{3}{*}{$\begin{array}{c}\text { SBL- } \\
653124355 \\
0\end{array}$} & $\begin{array}{l}\text { Frequency } \\
\text { range }\end{array}$ & $\begin{array}{c}65- \\
120 \mathrm{GHz}\end{array}$ \\
\hline & & & Gain & $35 \mathrm{~dB}$ \\
\hline & & & \begin{tabular}{|l|} 
Noise figure \\
\end{tabular} & $5 \mathrm{~dB}$ \\
\hline \multirow{3}{*}{ WG-BPF } & \multirow{3}{*}{$\begin{array}{c}\text { Eravant } \\
\text { (formerly SAGE } \\
\text { Millimeter) }\end{array}$} & \multirow{3}{*}{$\begin{array}{c}\text { SWF- } \\
10404340- \\
10-B 1\end{array}$} & $\begin{array}{l}\text { Bandpass } \\
\text { frequencies }\end{array}$ & $\begin{array}{c}98- \\
102 \mathrm{GHz}\end{array}$ \\
\hline & & & $\begin{array}{l}\text { Bandpass } \\
\text { insertion } \\
\text { loss }\end{array}$ & $2 \mathrm{~dB}$ \\
\hline & & & $\begin{array}{l}\text { Low } \\
\text { side/high } \\
\text { side } \\
\text { rejection }\end{array}$ & $40 / 40 \mathrm{~dB}$ \\
\hline
\end{tabular}

\subsection{AWRDE models and setups}

Fig. 5 depicts the AWRDE model of a 24-order frequency multiplier based on an MWE approach. The model under study includes a chain of frequency multipliers in the form of subcircuits (SUBCKT), bandpass filters (BPFD), and amplifier (LIN_S) library models in accordance with Fig. 3. For running a simulation experiment, two instrumental library models of RF oscillator (TONE) and RF spectrum analyzer (TP) are introduced on its input and output, correspondingly. The parameters of each element of the model are taken from Table 2. In the bottom of the figure, the output power values for each stage are marked.

It should be noted that each of the first three selected frequency multipliers is an integrated circuit containing the multiplying stage itself, located between the input and output amplifiers (Fig. 6).

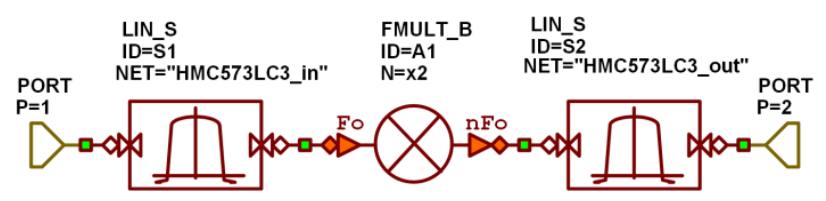

Fig. 6 - The schematic of each of the first three frequency multipliers

In addition, Fig. 7 depicts the AWRDE model of a 24-order frequency multiplier based on an MWP approach. The model under study includes a chain of subcircuits (SUBCKT) in accordance with Fig. 4 and Table 3. Namely, it contains the models of RF devices ("EA1", “EA2-1", “EA2-2", "RF BPF", “EA3", "WG BPF"), which are the same for Fig. 5, early proposed models of active optoelectronic devices $[23,24]$ such as semiconductor laser source ("Laser"), Mach-Zehnder modulators ("MZM1", "MZM2"), photodetectors ("PD1", "PD2"), and optical Bragg grating filter ("OBGF"), as well as equivalent optical elements such as splitter ("SPLIT2"), isolators ("ISOL8R"), amplifier ("OA"), and coaxial-to-waveguide adapter ("WG1"). The calculation of the elements of the last group, due to the work of AWRDE at the symbolic level (see Introduction), is performed in the same way as their microwave counterparts. The parameters of each element of the model are taken from Table 3. 


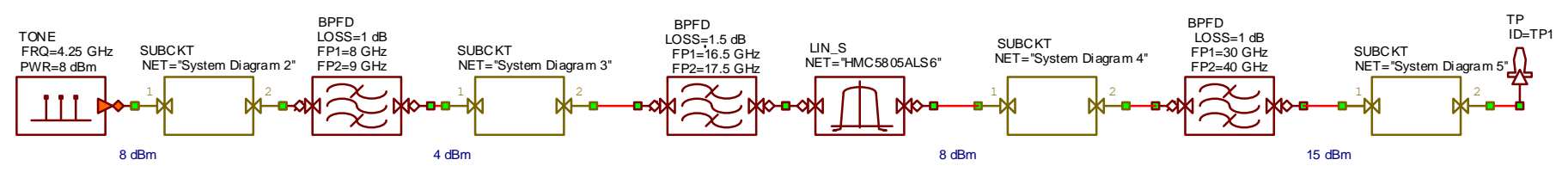

Fig. 5 - AWRDE setup of MWE approach-based frequency multiplier

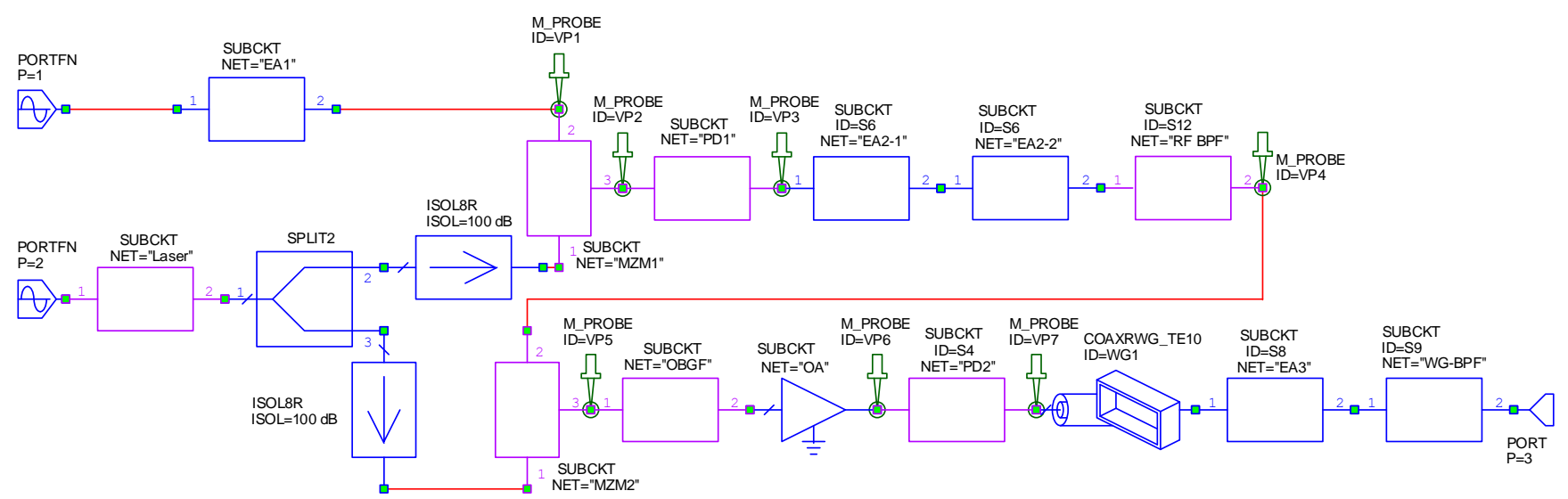

Fig. 7 - AWRDE setup of MWP approach-based frequency multiplier

Currently, the operating principles and features of the above optoelectronic devices are described in a large number of publications (see, for example, [15]). Nevertheless, for a better understanding, we believe it necessary to explain the operation of the Mach-Zehnder electro-optic intensity modulator in the modes of MATB and MITB used in this model. The basic circuit of MZM, is shown in Fig. 8.

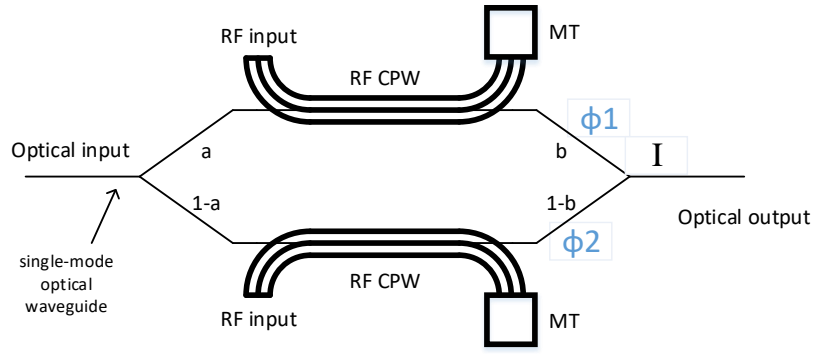

Fig. 8 - Basic circuit of MZMs used in MWP approach-based frequency multiplier

In the figure unmodulated laser emission is introduced through the input optical waveguide. In accordance with the principle of designing a widely-known Mach-Zehner interferometer (MZI), the optical circuit contains two planar single-mode waveguides formed in lithium niobate connected by input and output Y-couplers with branching coefficients "a" and " $b$ ". Depending on the phase difference between optical fields, $\varphi_{1}{ }^{-} \varphi_{2}$, the light can constructively or destructively interfere. An interaction with propagating an optical signal is performed by the coplanar waveguides (CPW) including the matched terminations (MT) on their ends. Assuming no loss in waveguides, the equality of dividing coefficients of both splitters, and ideal linear electro-optic effect, the transfer function of MZM will correspond to formula (1), where $\mathrm{V}$ is applied voltage, $V \pi$ is a so-called half-wave voltage related to control bias at which the phase difference in the two MZI arms reaches $180^{\circ}$.

$$
T_{M Z M}(V)=\frac{1}{2}\left\{1+\cos \left[\varphi_{0}+\frac{\pi V}{V_{\pi}}\right]\right\}
$$

Calculated by (1) taking into account the data in Table 3, the transfer characteristic of the MZM with the marked areas of MATB and MITB modes is shown in Fig. 9.

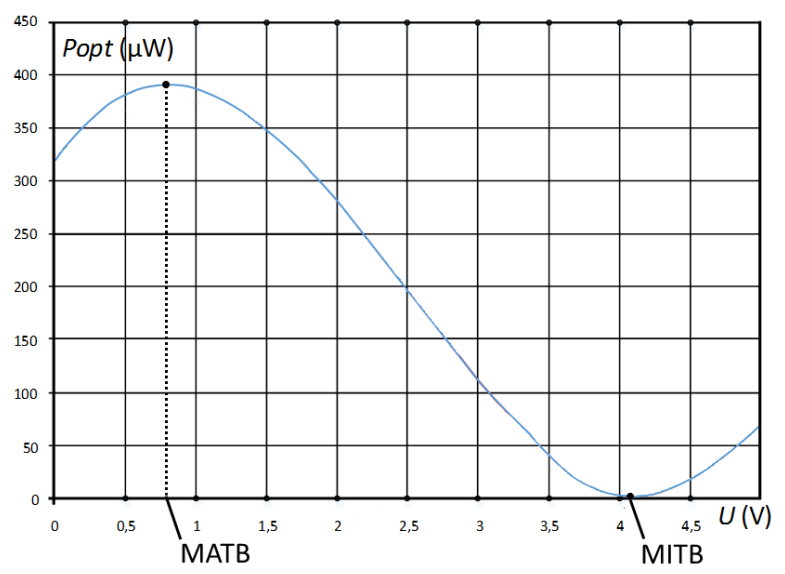

Fig. 9 - The transfer characteristic of the MZM

\subsection{Simulation results}

In the course of the simulation experiment, first, the spectra at the output of the frequency multiplier for the circuits in Fig. 3 and Fig. 4 were 
under study. The measurement results are shown in Fig. 10 (a) for an MWE approach and in Fig. 10 (b) for an MWP approach.

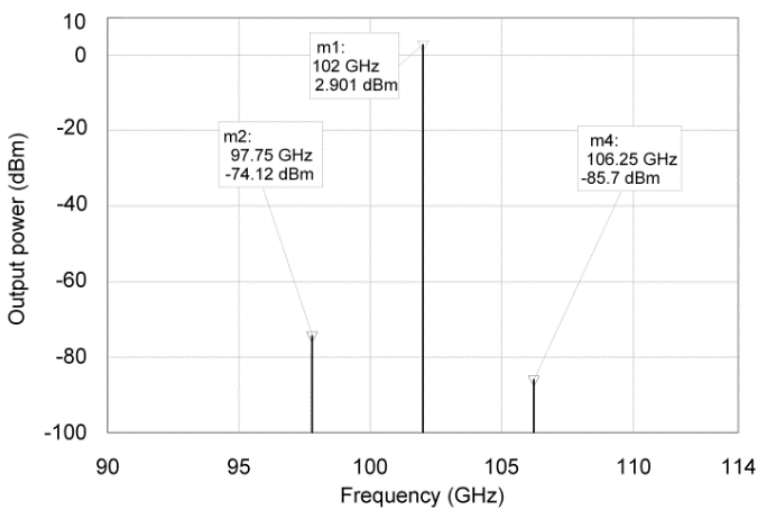

(a) For MWE model

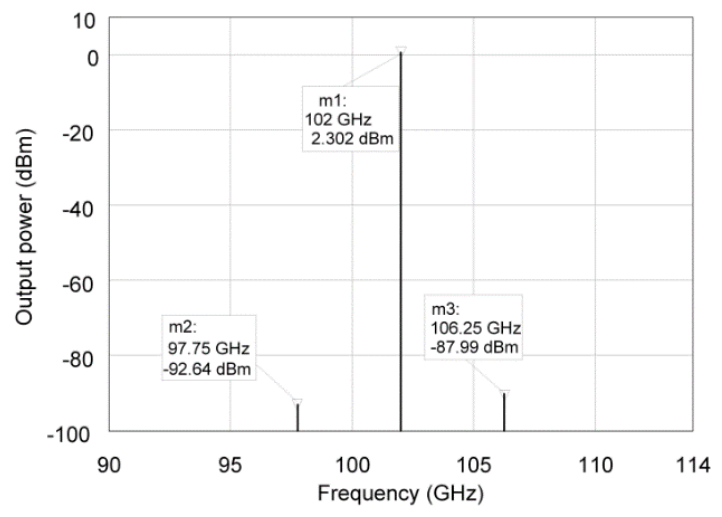

(b) For MWP model

Fig. 10 - Simulated output spectra for the frequency multiplier under study

In addition, their amplitude characteristics were investigated. The measurement results of output power vs input power are shown in Fig. 11.

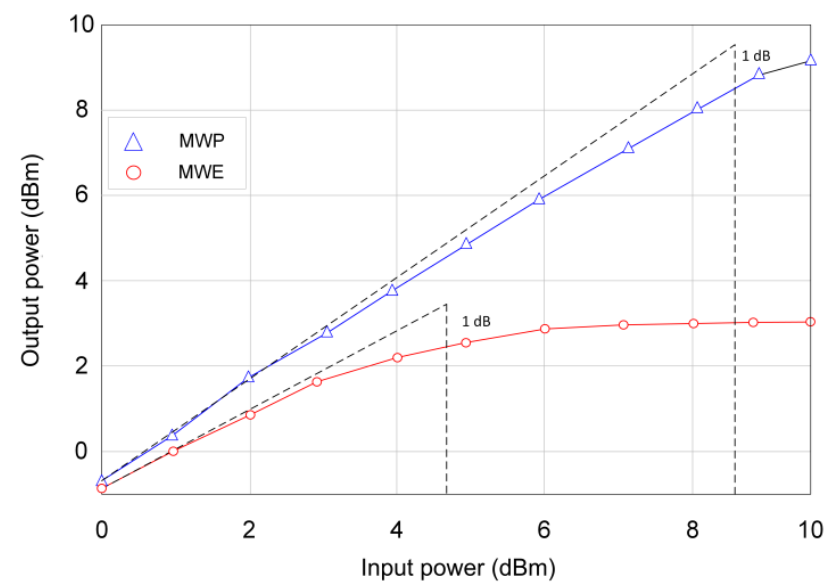

Fig. 11 - Amplitude characteristics for the frequency multiplier under study
The following outcomes can be drawn from these figures.

- The output spectra of both schemes under study have a high-side mode suppression ratio. Nevertheless, due to the higher linearity of the characteristics of the used optoelectronic devices, its minimum value for the MWP approach turned out to be $13 \mathrm{~dB}$ higher $(90 \mathrm{~dB}$ vs $77 \mathrm{~dB}$ ) than for the MWE approach.

- Measurement of the amplitude characteristics showed that the input power level of the MWPbased scheme according to the standard criterion, which is a $1-\mathrm{dB}$ deviation from linear, is almost $5 \mathrm{~dB}$ higher than that of the MWE-based scheme. Consequently, its dynamic band is significantly better.

\section{CONCLUSION}

To choose the optimal principle for designing B5G NG-RAN's radio unit circuitry using a microwaveelectronics (MWE) or microwave-photonics (MWP) approach, in this paper we performed a comparative simulation for a specific example of developing such an obligatory RU's node as a reference oscillator with an output frequency of more than $100 \mathrm{GHz}$, which was typically implemented by means of a circuit that includes a relatively low-frequency RF oscillator followed by a high-order frequency multiplier. In particular, we proposed and described two alternative schemes for implementing a frequency multiplier from 4.25 to $102 \mathrm{GHz}$ using an MWE or MWP approach. The goal of the simulation was to select an optimal design concept for developing a high-order $\mathrm{RF}$ multiplier of NG-RAN's reference oscillator using the same input and output powers and operating frequencies. For both cases, Cadence AWRDE software with an additional introduction of the previously proposed models of optoelectronic devices was implemented. To ensure the practical orientation of the simulation experiments, the parameters of the included active and passive schematic elements were selected based on the the specifications of commercially available discrete components.

As a result, a comparison of the investigated variants showed the potential advantage of the MWP approach from the point of view of the simplicity of the scheme, since even at the current level of optoelectronic device production, the 
multiplication of a higher order is essentially provided. This advantage will significantly increase as promising optoelectronic devices [30] are put into production and the operating frequencies of the B5G systems move into the submillimeter range. Another advantage is the significally wider dynamic range that cannot be achieved with the traditional MWE approach.

Our further research will focus on a detailed comparative study of the rest of the crucial features of the high-order frequency multipliers for 5G's fronthaul, in particular, on the phase noise characteristic that is one of the main limitations of frequency-multiplying chain in millimeter and submillimeter wavelength ranges, as well as on experimental verification of the simulated results.

\section{ACKNOWLEGMENT}

This work was supported by the Russian Foundation for Basic Research, Grant No. 18-29-20083.

\section{REFERENCES}

[1] 5G: The Latest News \& Updates. Available: https://www.lifewire.com/5g-news4428066

[2] Ahmet Yazar, Seda Doğan Tusha, Huseyin Arslan. "6G Vision: an Ultra-Flexible Perspective", in ITU Journal on Future and Evolving Technologies, Volume 1, Issue 1, p. 121-140, 2020.

[3] W. Saad, M. Bennis, M. Chen, "A Vision of 6G Wireless Systems: Applications, Trends, Technologies, and Open Research Problems", arXiv:1902.10265v1 [cs.IT], p. 1-9, 2019.

[4] Khaled B. Letaief, W. Chen, Y. Shi, J. Zhang, Y.J. A. Zhang, "The Roadmap to 6G: AI Empowered Wireless Networks", in IEEE Communications Magazine, p. 84-90, 2019.

[5] J. Zou, S. A. Sasu, M. Lawin, A. Dochhan, J.-P. Elbers, M. Eiselt, "Advanced optical access technologies for next-generation (5G) mobile networks", in Journal of Optical Communications and Networking, Vol. 12, No. 10, p. D86-D98, 2020.

[6] M. Giordani, M. Polese, M. Mezzavilla, S. Rangan, M. Zorzi, "Toward 6G Networks: Use Cases and Technologies", in IEEE Communications Magazine, p. 55-61, 2020.
[7] Final Acts WRC-2015. Resolution 238. World Radiocommunication Conference (WRC2015), 2016.

[8] Final Acts WRC-2019. Resolution 739. World Radiocommunication Conference (WRC2019), 2019.

[9] K. Nishimura, S. Ishimura, A. Bekkali, K. Tanaka, H. Hirayama, Y. Tsukamoto, S. Nanba, M. Suzuki "Optical Access Technology for B5G MFH/MBH", OFC 2019, W3J.1, p. 1-3, 2019.

[10] S. Chen, J. Zhao, "The requirements, challenges and technologies for $5 \mathrm{G}$ of terrestrial mobile telecommunication", in IEEE Communications Magazine 2014, 52, pp. 36-43, 2014.

[11] "Study on new radio access technology: radio access architecture and interfaces", 3GPP Technical Report TR38.801, v14.0.0, 2017.

[12] S. Noor, Ph. Assimakopoulos, M. Wang, H. A. Abdulsada, N. Genay, L. A. Neto, Ph. Chanclou, and N. J. Gomes, "Comparison of digital signal processing approaches for subcarrier multiplexed 5G and beyond analog fronthaul", in Journal of Optical Communications and Networking, Vol. 12, No. 3, p. 62-71, 2020.

[13] J. Zou, S. A. Sasu, M. Lawin, A. Dochhan, J.-P. Elbers, M. Eiselt, "Advanced optical access technologies for next-generation (5G) mobile networks", in Journal of Optical Communications and Networking, Vol. 12, No. 10, p. D86-D98, October 2020.

[14] D. Novak et al., "Radio-Over-Fiber Technologies for Emerging Wireless Systems", in IEEE Journal of Quantum Electronics, vol. 52, no. 1, pp. 1-11, Jan 2016.

[15] V. J. Urick Jr., J. D. McKinney, K. J. Williams, "Fundamentals of Microwave Photonics", Wiley Series in Microwave and Optical Engineering, Hoboken, New Jersey, pp. 467, 2015.

[16] M.E. Belkin, T. Bakhvalova, A.S. Sigov, "Design Principles of 5G NR RoF-Based Fiber-Wireless Access Network", in book Recent Trends in Communication Networks, IntechOpen, London, UK, p. 121-145, 2020. 
[17] M. Kamalian-Kopae, M.E. Belkin, S.K. Turitsyn, "The Design Principles of FibreWireless Integration in the Incoming Mobile Communication Networks", in Proceedings of $22^{\text {nd }}$ International Conference on Transparent Optical Networks (ICTON 2020), Bari, Italy, July 19-23, p. 1-4, 2020.

[18] M.E. Belkin, D. Fofanov, T. Bakhvalova, A.S. Sigov, "Design of Reconfigurable MultipleBeam Array Feed Network based on Millimeter-Photonics Beamformers", in Array Pattern Optimization, IntechOpen: London, United Kingdom, Volume 1, pp. 109132., 2019.

[19] M.E. Belkin, A.S. Sigov, "The building principles of a cost-And power-efficient base station for emerging fiber-wireless networks", 2017 IEEE International Conference on Microwaves, Antennas, Communications and Electronic Systems (COMCAS 2017), Tel Aviv, Israel, November 13-15,pp. 1-4, 2017.

[20] M.E. Belkin, T. Bakhvalova, S. Turitsyn, A. Sigov, "The Design Principles of Reconfigurable Versatile Base Station for Upcoming Communication Networks", 26th Telecommunications Forum (TELFOR2018), Belgrade, Serbia, pp. 180-182, 2018.

[21] M. E. Belkin, A. Alyoshin, D Fofanov, "Designing WDM-RoF Concept-Based FullDuplex MMW Fiber Fronthaul Microcell Network", 26th Conference of Open Innovations Association (FRUCT2020). Yaroslavl, Russia, April 20-24, 2020.

[22] X. J. M. Leijtens, P. Le Lourec, M. K. Smit, "SMatrix Oriented CAD-Tool for Simulating Complex Integrated Optical Circuits", in IEEE Journal of Selected Topics in Quantum Electronics, pp. 257-262, 1996.

[23] M.E. Belkin, V. Golovin, Y. Tyschuk, M. Vasil'ev, A.S. Sigov, “Computer-Aided Design of Microwave-Photonics-based RF Circuits and Systems", chapter in Intech Open book RF Systems, Circuits and Components, Chapter 4, pp. 61-81, 2018.

[24] M.E. Belkin, T. N. Bakhvalova, V. Golovin, Y.N. Tyschuk, A.S. Sigov, "Modeling and Simulation in Microwave-Photonics Applications", chapter in IntechOpen book Modeling and Simulation in Engineering Selected Problems, p. 167-188, 2020.
[25] M. Belkin, T. Bakhvalova, A.S. Sigov, "Studying an Optimal Approach to Distribute Signals through Fiber-Wireless Fronthaul Network", COMCAS-2019, November 4-6, Tel Aviv, Israel, 2019.

[26] A.J. Seeds, K.J. Williams, "Microwave Photonics", in IEEE/OSA Journal of Lightwave Technology, v. 24, No 12, p. 4628-4641, 2006.

[27] J. Capmany, D. Novak, "Microwave photonics combines two worlds", in Nature Photonics, Vol. 1, No. 1, pp.319-330, 2007.

[28] N. Sarmah, B. Heinemann, U.R. Pfeiffer, "235$275 \mathrm{GHz}(\mathrm{x} 16)$ frequency multiplier chains with up to $0 \mathrm{dBm}$ peak output power and low DC power consumption", 2014 IEEE Radio Frequency Integrated Circuits Symposium, June 1-3, Tampa, USA, p. 181-184, 2014.

[29] A. Kanno; T. Kawanishi, "Millimeter-wave signal generation using cascaded optical frequency multiplication technique", 2014 44th European Microwave Conference, October 6-9, Rome, Italy, p. 1028-1031, 2014.

[30] M. Burla, C. Hoessbacher, W. Heni, C. Haffner, Y. Fedoryshyn, D. Werner, "A $325 \mathrm{GHz}$ Analog Photonic Link", 2019 International Topical Meeting on Microwave Photonics (MWP), October 7-10, Ottawa, Canada, p. 1-4, 2019.

\section{AUTHORS}

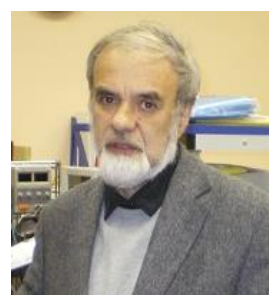

Prof. Dr. Mikhail E. Belkin received an engineering degree in radio and television from Moscow Institute of Telecommunications, in 1971, Ph. D. degree in telecommunication and electronic engineering from Moscow Technical University of Telecommunications and Informatics, in 1996, and Sc. D. degree in photonics and optical communications from Moscow State Technical University of Radio-Engineering, Electronics and Automation, in 2007. The theme of his Sc. D. degree thesis is 'Analog Fiber Optic Systems with multiplexing on RF and Microwave Subcarriers and Multiservice HFC Networks on their Base'. He has written more than 250 scientific works in English and Russian. The major current R\&D fields are fiber-optic devices and systems, microwave photonics, photonic ICs, incoming cellular communication networks, computer-aided design. 
At present, M. E. Belkin is the Director of the Scientific and Technological Center "Integrated Microwave Photonics", Professor of the department "Optical and Optoelectronic Devices and Systems", Institute of Physics and Technology, MIREA - Russian Technological University, and he is a member of IEEE's MTTS, LEOS (now PhS), and COMSOC from 2006, and a member of OSA from 2018.

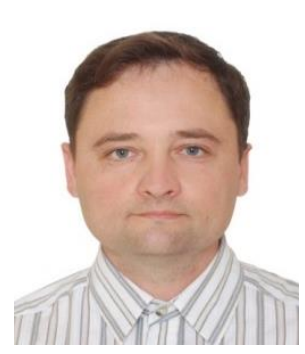

Dr. Vladislav Golovin graduated from Sevastopol State University in 2000, received a $\mathrm{PhD}$ in engineering in 2004, and works at Sevastopol State University since 2004 as an associate professor of the Department of Radio Electronics and Telecommunications. He is a co-author of three monographs published by IntechOpen, 55 papers in the Scopus database. His main research interests are microwave equipment, radio engineering, microwave-photonics, and telecommunication technologies.

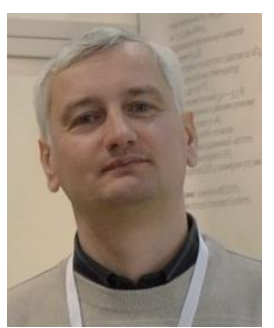

Yuriy Tyschuk graduated from Sevastopol State University in 2004, and works at Sevastopol State University since 2007 as a senior lecturer of the Department of Radio Electronics and Telecommunications. He is a coauthor of 3 monographs published by IntechOpen, 38 papers in the Scopus database. His main research interests are microwave equipment, radio engineering, microwave-photonics, and telecommunication technologies.

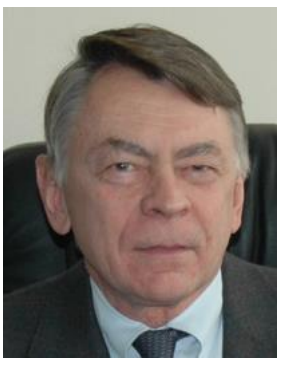

Professor Dr. Alexander. S. Sigov is an expert in Solid State Physics and Electronics. He contributed extensively to the phenomenology of magnets, ferroelectrics and multiferroics, physics of ferroic-based heterostructures, thin films, etc. The results of his scientific activity are reflected in more than 300 papers, reviews, book chapters, 19 monographs and textbooks, including the well-known "Defects and Structural Phase Transitions" together with A. Levanyuk. For many years, he has chaired the Department of Nanoelectronics in MIREA. He created his own school, inspiring and mentoring many talented scientists. In 2006, he was elected a Member of the Russian Academy of Sciences. He is the head of the Russian Academy Council on Dielectrics and Ferroelectrics, member of numerous scientific societies, Associate Editor of international journals Ferroelectrics and Integrated Ferroelectrics, Editor and member of Boards of more than ten Russian national journals, Chair of the Council on Physics and Astronomy of the Russian Foundation for Basic Research. At present, Alexander Sigov is the Head of Nanoelectronics Dept. and President of MIREA - Russian Technological University, Moscow, Russia, Doctor of Physics, and Fellow member of the Russian Academy of Sciences. 